\title{
Inovações em Psicologia Escolar: o contexto da educação superior
}

\author{
Innovations in School Psychology: The \\ context of higher education
}

Claisy Maria MARINHO-ARAUJO ${ }^{1}$

\begin{abstract}
Resumo
A educação superior, tanto no Brasil quanto no exterior, tem sido alvo de inúmeras políticas educacionais contemporâneas. O sistema brasileiro ampliou-se velozmente na última década, ocasionando transformações institucionais no âmbito político-pedagógico e acadêmico, bem como no perfil dos estudantes. As mudanças têm como foco o direito de acesso acadêmico e a democratização de oportunidades. A expansão do ensino tornou-se uma urgente meta orientadora de decisivas ações governamentais. A consequente massificação agudizou, no espaço educativo das Instituições de Ensino Superior, as tensões e contradições, mas, também, as potencialidades para o desenvolvimento pessoal e as emancipações inerentes a esse contexto. Defendendo que a educação superior apresenta-se como fértil campo para a ação da Psicologia Escolar, apresenta-se, neste artigo, um modelo de atuação baseada em cinco eixos principais: 1) Mapeamento Institucional; 2) Escuta Psicológica; 3) Gestão de Políticas, Programas e Processos Educacionais; 4) Propostas Pedagógicas e Funcionamento de Cursos; 5) Perfil do Estudante. Essas reflexões e propostas para pesquisa e intervenção na área, fundamentadas pela Psicologia Histórico-cultural do desenvolvimento humano, enfatizam a mediação intencional do psicólogo no desenvolvimento dos atores educacionais. Como conclusão, destaca-se que a intervenção institucional e coletiva do psicólogo escolar deva estar voltada tanto à conscientização e ao empoderamento dos sujeitos, como às transformações sociais emancipadoras e ao sucesso acadêmico.
\end{abstract}

Palavras-chave: Educação superior; Prática institucional; Psicologia escolar.

\begin{abstract}
The higher education, both in Brazil and abroad, has been targeted by countless contemporary educational policies. Brazil's educational system has improved considerably over the past decade, causing institutional changes both in the political-pedagogical and in the academic scope, as well as in the students' profiles. The changes aim at the right to academic access and at the democratization of opportunities. The expansion of the education has become a toppriority compelling goal guiding decisive governmental actions. The subsequent massification in the educational scope of Higher Education Institutions has sharpened the tensions and contradictions, but it has also increased the potentialities for personal development and emancipation inherent to this context. Understanding that higher education is itself fertile ground for School Psychology to take action, this article presents an action plan based on five main axes: 1) Institutional Mapping; 2) Psychological Listening; 3) Policies, Programs and Educational and Processes Management;

$\nabla \nabla v$

1 Universidade de Brasília, Instituto de Psicologia, Programa de Pós-Graduação em Processos de Desenvolvimento Humano e Saúde. Campus Darcy Ribeiro, Instituto Central de Ciências Sul, prédio Minhocão, Asa Norte, 70910-900, Brasília, DF, Brasil. E-mail: <claisy@unb.br>.
\end{abstract}


4) Pedagogical Proposals and Course Scheme; 5) Student Profile. These considerations and proposals of research and intervention in this field, based on the Cultural-historical Psychology of human development, emphasize the psychologist's intentional mediation in the development of the educational actors. As a conclusion, we highlight that the institutional and collective intervention of the school psychologist should not only be turned toward the awareness and empowerment of the subjects, but also to the emancipating social changes and academic success.

Keywords: Education, Higher; Institutional practice; School psychology.

O objetivo deste artigo é apresentar a Psicologia Escolar, considerada como campo de pesquisa, reflexão, produção de conhecimento e de intervenção profissional, inserida no contexto da educação superior, prospectando avanços ao campo científico e à atuação profissional na área. Partindo dessa defesa, o modelo teórico-interventivo proposto por Marinho-Araujo (2009, 2014a) para subsidiar ações e contribuições do psicólogo escolar na educação superior será apresentado, revisto e ampliado.

A história oficial da Psicologia no Brasil data de 1962, quando houve a legalização da área no âmbito científico e na prática profissional. Uma retrospectiva dessa história, no entanto, aponta que são recentes as transformações na pesquisa, na formação e na atuação vinculadas, principalmente, às responsabilidades e compromissos sociais contemporâneos, demandadas ao conhecimento e à atuação psicológica crítica (Martín-Baró, 1996; Parker, 2007). A Psicologia Escolar acompanhou essa historicidade, ressignificando construções epistemológicas, teóricas e intervenções práticas, associando-as à parcerias institucionais e coletivas nos contextos educacionais. Essas ações focaram o empoderamento dos atores escolares, a conscientização de suas potencialidades e sucessos, visando transformações sociais para muitos.

A escola tem sido amplamente defendida na área como contexto privilegiado para a atuação do psicólogo escolar. No entanto, é possível verificar que a Psicologia Escolar, na última década, vem comparecendo com mais expressividade em diversificados espaços institucionais, como creches, cursos de línguas, escolas de medidas socioeducativas, orfanatos, associações socioculturais, organizações não governamentais, serviços públicos de educação diversas outras instituições - assistenciais, empresariais, filantrópicas ou outras de cunho educativo. Igualmente, despontam contemporaneamente modalidades de ensino que não eram foco de atuação da área, como a educação de jovens e adultos, o ensino superior e a educação à distância (Bisinoto \& Marinho-Araujo, 2014; Marinho-Araujo, 2009, 2010, 2014a, 2014b; Marinho-Araujo \& Almeida, 2005).

A literatura nacional e internacional da área identifica a educação superior como um contexto procurado para a pesquisa em Psicologia. No entanto, geralmente é utilizado na coleta de dados com entrevistas ou aplicação de instrumentos a estudantes, professores e gestores. Verifica-se, na literatura, que ainda são pouco explorados os trabalhos que apontam a educação superior enquanto um campo de atuação profissional para a Psicologia Escolar, coadunado às proposições teóricas e práticas atualmente defendidas para a área. O levantamento bibliográfico de teses de doutorado, dissertações de mestrado e artigos de revistas científicas de Psicologia e Educação, cobrindo cinco anos (1995-1999), realizado por Bariani, Buin, Barros e Escher (2004), mostrou que, entre os temas abordados, algumas práticas do psicólogo escolar na educação superior apareciam de forma incipiente e, quando apresentados, centralizavam o enfoque da atuação no aluno. Mais recentemente, Maroldi (2012) e Nunes, Alves, Ramalho e Aquino (2014) realizaram uma análise bibliométrica e uma pesquisa das produções científicas da Psicologia Escolar disponibilizadas, por exemplo, nas Bases de Dados da Biblioteca Virtual em Saúde Psicologia Brasil. Nesses levantamentos, o ensino superior não é apontado como contexto de atuação profissional do psicólogo escolar.

Nas produções acadêmicas nacionais, as contribuições mais efetivas que relatam a especi- 
ficidade da atuação do psicólogo escolar na educação superior são encontradas em: Bisinoto \& Marinho-Araujo, 2011a, 2011b, 2014; Bisinoto, Marinho-Araujo, \& Almeida, 2011; Caixeta \& Sousa, 2013; Marinho-Araujo, 2009, 2010, 2014a; Sampaio, 2009, 2010; Serpa \& Santos, 2001; Witter, 1999; Zavadski \& Facci, 2012. Essa literatura apresentou temáticas distintas: possibilidades de práticas realizadas pelo psicólogo escolar; serviços de orientação ao estudante universitário; formação docente; atuação do psicólogo escolar frente às políticas acadêmicas e estudantis de ações afirmativas voltadas para a permanência dos estudantes; e atuação institucional da Psicologia Escolar ampliada coletivamente.

No cenário internacional, com o auxílio do Comitê de Investigação da Associação Internacional de Psicologia Escolar, estudos transculturais foram construídos para investigar informações acerca das práticas da Psicologia Escolar em diferentes países da América do Norte, Europa, Ásia e África. De modo geral, os resultados apontam para práticas dos psicólogos escolares localizadas em níveis iniciais de escolarização, voltadas ao atendimento individualizado de crianças a partir de demandas escolares, à avaliação psicológica (dificuldades de aprendizagem e encaminhamentos para educação especial) e ao aconselhamento psicológico.

Referenda-se, ainda, o trabalho de Price, Floyd, Fagan e Smithson (2011). Esse estudo teve como objetivo identificar os 100 artigos mais citados na literatura internacional sobre Psicologia Escolar entre os anos 1960 e 2000, bem como os 25 artigos mais citados no período de 1999 a 2009, em cinco revistas com alto valor de impacto na Psicologia: Journal of School Psychology, Psychology in the Schools, School Psychology International, School Psychology Quarterly e School Psychology Review. Em nenhum dos títulos apresentados nos resultados há indicações de estudos sobre a atuação do psicólogo escolar na educação superior.

Apesar dessas evidências, alguns relatos de trabalhos aparecem na literatura internacional. De um lado, os psicólogos trabalham ligados a uma vertente clínico-terapêutica, privilegiando a assistência aos estudantes em momentos de crise ou tra- balhando com o professor em situações semelhantes (Dole, 1981); de outro, no âmbito de um trabalho indireto, atuam no acompanhamento ao desenvolvimento de estudantes, professores e outros membros do corpo acadêmico e administrativo visando o aumento da efetividade educacional (Farrell, Jimerson, Kalambouka, \& Benoit, 2005; Sandoval \& Love, 1977). Atividades ligadas à avaliação educacional (de curso ou do desempenho docente na percepção de alunos) e à utilização de instrumentos de intervenção de base metodológica qualitativa (questionários, entrevistas, vídeos, seminários, instrumentos para acompanhamento da trajetória acadêmica e outros) são os pontos comuns relatados (Sandoval \& Love, 1977).

Entre as experiências internacionais mais contemporâneas, tem-se na Rede de Serviços de Apoio Psicológico no Ensino Superior (2006) uma das mais estruturadas iniciativas de visibilidade para a atuação da Psicologia Escolar no ensino superior. No entanto, o enfoque da atuação psicológica nesses serviços é individualizante, especialmente voltado ao aconselhamento e acompanhamento ao estudante, com o objetivo de favorecer sua transição e adaptação à vida universitária (Rede de Serviços de Apoio Psicológico no Ensino Superior, 2002).

Outra experiência europeia de atuação psicológica no ensino superior é descrita por Ferrer-Sama (2008) ao divulgar os trabalhos do Fórum Européen d'Orientation Académique, uma organização de apoio aos estudantes da Educação Superior criada em 1988 e composta por representantes de todos os países da comunidade europeia, com atividades desenvolvidas pelos Serviços de Orientação e Aconselhamento aos alunos da educação superior. Ferrer-Sama (2008) observa que, de modo geral, a intervenção é individual, focada no problema que motivou os estudantes a buscarem ajuda profissional.

A realização desse levantamento da literatura objetivou justificar a relevância científica e profissional da reflexão, da pesquisa e da proposição de formas inovadoras de intervenções psicológicas nesse campo de ensino, desvinculadas da patologização e da psicologização individual. Essas novas 
formas de atuação devem influenciar transformações estruturais, funcionais e relacionais nas Instituições de Ensino Superior (IES); favorecer mediações no desenvolvimento de vários atores, para além do estudante; e impactar muitos, promovendo conscientização, de uma forma dialética, de cada sujeito e de todo o coletivo na instituição. Coadunada a essa perspectiva ampla de atuação e expansão da Psicologia Escolar, tendo seus objetos de ação e de pesquisa direcionados à educação superior, é que vêm sendo defendidas propostas teóricas, práticas e de pesquisa (Marinho-Araujo, 2009, 2014a). Esse modelo fundamenta-se na Psicologia Crítica (Martín-Baró, 1996; Parker, 2007) e nos aportes epistemológicos e teóricos da Psicologia Histórico-Cultural do Desenvolvimento Humano (Vygotsky, 1926/1999, 1926/2003, 1931/2000), com atividades que enfatizam o coletivo institucional, buscando engajamento crítico e político dos sujeitos nas transformações subjetivas e socioculturais.

Evidencia-se, com base nesses pressupostos, a concepção da referida proposta de atuação, que considera as especificidades e características de cada IES. Essa perspectiva institucional é contextualizada e ressignificada dinamicamente pelos sujeitos que transformam, dialeticamente, ações, tempos e espaços coletivos. Ainda que sejam considerados os planejamentos institucionais, projetos pedagógicos de cursos, compromissos, missões, objetivos, prospecções, metas, desafios e conquistas das IES, o foco da atuação do psicólogo não se desvincula dos perfis, demandas, expectativas, desejos e intencionalidades de seus atores. Acompanhando, portanto, os estudos, produções e pesquisas de Marinho-Araujo (2009, 2014a), os quais prenunciaram avanços para a área, iniciando, no país, a defesa da atuação da Psicologia Escolar na educação superior, o presente artigo objetiva retomar o modelo defendido pela autora para ampliar ações e contribuições a serem oportunizadas pelo psicólogo escolar na educação superior.

\section{Propostas de atuação para a Psicologia Escolar na educação superior}

A forte expansão da educação superior, que 202 vem ocorrendo no país nos últimos 10 anos, resultou no cenário registrado recentemente pelo Censo de 2012 (Instituto Nacional de Estudos e Pesquisas Educacionais Anísio Teixeira, 2014): há um total de 7037688 alunos matriculados em cursos presenciais e a distância; dessas matrículas, 1897376 são em IES públicas e 5140312 em privadas. O ensino presencial conta com 5746762 alunos, enquanto 992927 estão matriculados na educação à distância. Das atuais 2416 IES, 2112 são privadas (87,4\%) e 304 públicas (12,6\%); no entanto, estas últimas, por serem de maior porte, concentram $34,0 \%$ dos cursos de graduação.

As Instituições de Ensino Superior ofertam ao todo 32050 cursos, dos quais 67,1\% são de bacharelado, 19,5\% de licenciatura e 13,5\% tecnológicos. Em relação aos cursos à distância, o Censo refere uma participação superior a 15,0\% das matrículas nesses cursos; destes, 40,4\% estão em cursos de licenciatura, sinalizando o aumento da procura pela formação de professores para a educação básica no país. As IES agregam, no total, 362732 docentes, $45,2 \%$ do sexo feminino e $54,8 \%$ do masculino; 41,4\% estão em instituições públicas e $58,6 \%$ em privadas. Nas primeiras, $51,4 \%$ são doutores e $91,1 \%$ trabalham em regime de tempo integral. Já nas IES privadas, esse número cai consideravelmente: 17,8 e $24,2 \%$, respectivamente (Instituto Nacional de Estudos e Pesquisas Educacionais Anísio Teixeira, 2014).

A expansão se anuncia também em outros indicadores que, para além dos números, sugerem novos desenhos sociopolíticos na oferta da educação superior. Um deles é a interiorização do sistema. Embora a região Sudeste tenha um número significativo de matrículas ofertadas no país (40,5\%), a região Nordeste vem crescendo $(28,4 \%)$, colocando-se à frente da região Sul nesse indicador $(13,9 \%)$ (Instituto Nacional de Estudos e Pesquisas Educacionais Anísio Teixeira, 2014).

Essa massificação e democratização do ensino superior criou, para além de vagas e acesso, demandas acríticas e equivocadas por atendimentos psicológicos voltados a "adequação" do novo contingente de estudantes às exigências de um mundo acadêmico complexo. Políticas como Reuni (Brasil, 2005), Prouni (Brasil, 2007) e Lei das Cotas (Brasil, 
2012) abriram importantes espaços para estudantes vindos de escolas públicas, com baixas condições socioeconômicas e com outras características que os excluíam desse cenário. Diante dessa nova configuração no campus, houve também uma inesperada ampliação da procura por psicólogos escolares na educação superior, pressupondo-se que os novos perfis estudantis, aliados às configurações e exigências acadêmicas, iriam requerer desse profissional "tratamento" para os "futuros, possíveis e previsíveis" problemas de aprendizagem, defasagens acadêmicas e inadequação social.

Esse tipo de demanda, bem parecida com aquelas das décadas de 1970 e 1980, relembra uma compreensão míope e equivocada dessa atuação, voltada basicamente para cuidar e adaptar manifestações individuais dos chamados "insucessos acadêmicos" (Almeida, Marinho-Araujo, Amaral, \& Dias, 2012), desconsiderando influências culturais, históricas e sociopolíticas na sua produção. Tais demandas coadunam-se à presença de uma Psicologia acrítica, voltada para a remediação de problemas, a minimização de conflitos e para a adaptação de estereotipias.

No contraponto dessa tendência, os estudos de Marinho-Araujo (2009, 2014a) têm defendido que os espaços abertos à Psicologia Escolar, a partir da democratização do ensino superior no país, devem ser ocupados, principalmente, nas brechas e rachaduras que as contradições impingem às ideologias hegemônicas. Essas rupturas devem ser alargadas por meio de uma atuação pautada na ética e na criticidade, com fundamentações teoricoconceituais que instrumentalizem a transformação social, a conscientização e o empoderamento de todos os atores desse contexto, em prol de um protagonismo coletivo para mudanças institucionais inclusivas, dignas e justas.

Defende-se que a Psicologia Escolar na educação superior deva atuar no desenvolvimento psicológico complexo dos participantes desse espaço. A filiação epistemológica e teórica adotada neste artigo fundamenta-se na Psicologia Histórico-cultural do desenvolvimento humano, a qual defende que as mediações intencionalmente planejadas em situações sociais de desenvolvimento opor- tunizam vivências em prol da conscientização (Vygotsky, 1931/2000).

O reconhecimento do desenvolvimento humano como um processo histórico, amalgamado pelas influências culturais e sociais dos contextos e das relações partilhados entre os sujeitos, é amplamente fundamentado pela abordagem histórico-cultural, tendo como principais representantes Vygotsky (1926/1999, 1926/2003, 1931/2000), Luria (1990) e Leontiev (2004). Tal abordagem favorece a atuação dos psicólogos escolares, por permitir-Ihes a autoria nas mudanças e a transformação de paradigmas tradicionais acerca das concepções de desenvolvimento psicológico, tornando possível oxigenar e renovar o processo educacional.

Entender o sujeito com base na abordagem histórico-cultural pressupõe compreendê-lo subjetivamente na sua própria história, a partir de complexos processos de significados e sentidos que vão transformando, dialeticamente, tanto os processos sociais quanto os individuais. Para essa perspectiva teórica, os avanços psicológicos ocorrem em função dos contextos e das relações socioculturais, em interdependência com o funcionamento orgânico e o aparato biológico dos sujeitos, induzindo o aparecimento de várias funções mentais superiores. Nessa direção, a abordagem histórico-cultural do desenvolvimento psicológico fornece à Psicologia Escolar pressupostos e fundamentos para subsidiar um olhar sustentado em concepções ativas acerca da potência desse processo, considerando a importância da mediação psicológica junto aos sujeitos em específicas situações sociais de desenvolvimento.

É fundamental que a mediação defendida por Vygotsky (1926/1999, 1926/2003, 1931/2000), como processo central das transformações inter e intrapsicológicas, enfatize a desnaturalização, o estranhamento, a inquietação e a desalienação (Martin-Baró, 1996) acerca de mecanismos coercitivos, adaptacionistas, deterministas e preconceituosos de dominação os quais comparecem na educação superior, subjacentes às concepções de desenvolvimento e de aprendizagem e às práticas acadêmicas. Para isso, é imprescidível que o psicólogo escolar fundamente-se nas contribuições dessas teorias psicológicas acerca da função da apren- 
dizagem no desenvolvimento psicológico humano adulto para promover, nesse contexto, processos de criticidade e engajamento aos que participam nas IES (Marinho Araujo, 2009, 2010, 2014a).

Ao trabalhar em prol da conscientização dos sujeitos, intervindo em complexos processos subjetivos nos diversos contextos institucionais e coletivos no interior das IES, o psicólogo escolar estará mediando com intencionalidade o desenvolvimento humano para muitos, abrangendo, na rede intersubjetiva institucional, uma ação política de transformação pessoal e social dos sujeitos - alunos, equipe pedagógica, família e demais atores socioinstitucionais (Marinho-Araujo, 2009, 2014a; Guzzo \& Mezzalira, 2011). Os caminhos para a intervenção desse profissional devem, portanto, estar ancorados na potencialidade de situações sociais de desenvolvimento que oportunizem vivências que engendram, de forma interdependente, ressignificações e circulação de sentidos na constituição subjetiva dos sujeitos em suas relações históricas e culturais, gerando processos de conscientização (Vygotsky, 1926/1999, 1926/2003, 1931/2000).

A materialização das diversificadas ações coletivas a serem desenvolvidas pelo psicólogo escolar na educação superior poderá contemplar os seguintes eixos: 1) Mapeamento Institucional; 2) Escuta Psicológica 3) Gestão de políticas, programas e processos educacionais; 4) Propostas pedagógicas e funcionamento de cursos; 5) Perfil do estudante (Marinho-Araujo, 2009, 2014a; Marinho-Araujo \& Almeida, 2005).

É importante considerar que tais eixos não se apresentam como etapas hierarquizadas e estanques em escala sequencial de prioridades. Eles devem ocorrer de forma integrada, articuladas à realidade e à dinâmica das IES, dialeticamente ressignificadas em função dos contextos, tempos e espaços, considerando os sujeitos e suas características pessoais e profissionais ao longo da ação psicológica. Como é inerente a toda ação da Psicologia Escolar, essas também devem ser atividades previamente discutidas, explicadas e negociadas com os gestores e demais profissionais das IES. Detalha-se, a seguir, sugestões operacionais para o delineamento do trabalho em cada uma dessas dimen- sões, recuperando, revendo, integrando e ampliando as proposições de Marinho-Araujo (2009, 2014a, 2014b).

\section{Mapeamento institucional}

Na intervenção institucional, o mapeamento e a análise dos contextos devem ser ações indispensáveis à adequada compreensão da realidade. Essa etapa não deve se caracterizar apenas como uma ação inicial do psicólogo, somente como um "levantamento de necessidades" ou um "diagnóstico prévio". É uma ação histórica que acompanha, dinamicamente, todas as formas de atuação do psicólogo escolar ao longo do ano letivo. As mudanças que ocorrem cotidianamente nos cenários educativos exigem um olhar atento e ágil e uma sensibilidade apurada para incluir essas modificações às análises e reflexões já realizadas, ressignificando-as para orientar novas ações.

Nessa perspectiva histórica, o mapeamento não se reduz a um questionário, protocolo ou relatório que se elabora e preenche no início do ano a partir da observação de algumas rotinas acadêmicas, ainda que acrescido de entrevista com os profissionais. Os registros formais do mapeamento são importantes e necessários, mas não devem reduzir-se a anotações pontuais e estanques de eventos circunstancializados ou situações de destaque. Ao contrário, ele se atualiza constantemente, a partir das inovações, avanços, contradições, rupturas, reformulações e conflitos ocorridos.

O mapeamento deve constituir-se, portanto, em uma ação de suporte à toda prática do psicólogo, revitalizando seu olhar e suas competências à medida que o contexto é atualizado e ressignificado pelas ágeis e diversificadas mediações inter-subjetivas das quais também participa. Assim, a permanente reflexão sobre os aspectos institucionais oportunizada pelo mapeamento, realizado de forma ampla, sistemática, dinâmica e contínua ao longo de todo o processo nos meses de trabalho, leva a constantes e renovados direcionamentos do planejamento e das práticas dos psicólogos em sua atuação com o coletivo da escola. Como exemplos para a operacionalização dessa dimensão sugere-se: 
Análise da conjuntura histórica, econômica, política, geográfica e social na qual a IES e seus participantes estão inseridos. Podem ser estudadas, por exemplo, características do contexto sociodemográfico da IES; dinâmica de funcionamento (cursos, turnos); espaço físico; recursos humanos (docentes, discentes, servidores, especialistas); relação com órgãos públicos de regulação, controle, manutenção e fomento; parcerias com a comunidade; outros. Esse conhecimento deve ser constantemente atualizado para oferecer informações claras a respeito dos desdobramentos dessas influências nas concepções que transversalizam as situações, aprendizagens e circunstâncias acadêmicas.

Análise documental para investigar as convergências, incoerências, aproximações e inovações existentes entre as normas prescritas e as reais práticas educativas, os discursos e as concepções dos atores educacionais que possam indicar caminhos às transformações institucionais e processos de conscientização mediados pela Psicologia Escolar. É útil evidenciar influências ideológicas, filosóficas, epistemológicas e políticas presentes nos diversos aspectos institucionais e normatizados por diretrizes pedagógicas como: Projeto de Desenvolvimento Institucional; Projeto Pedagógico Institucional; Projetos Pedagógicos dos Cursos; Regimentos, estatutos e legislações diversas. Na análise desses e de outros documentos, o psicólogo deverá buscar subsídios tanto para a clarificação das possíveis contradições entre o discurso e a prática, quanto para aproximações entre as diretrizes e o planejamento intencional de ações profissionais que originem autonomia, pensamento crítico, criatividade e equidade nos processos de ensino e de aprendizagem.

Observações institucionais interativas para orientar as participações no currículo, vivificado pelas amplas e múltiplas expressões as quais ocorrem nas práticas pedagógicas, nas rotinas de sala de aula, nos projetos e tendências educacionais. Essas observações poderão favorecer análises e reflexões contextualizadas acerca da estrutura e da dinâmica do trabalho pedagógico, da organização temporal e espacial de atividades, projetos e pes- quisas, das concepções de escola, educação, ensino, desenvolvimento, aprendizagem e avaliação que se presentificam subjacentes às práticas acadêmicas. A participação do psicólogo como observador ativo poderá ocorrer em vários espaços: rotinas formais e informais, momentos conversacionais, reuniões de colegiados e grupos de trabalho para elaboração ou definição de indicadores e diretrizes para subsidiar decisões micro e macro institucionais; fóruns de deliberações e decisões; parcerias institucionais; processos de internacionalização; ações de ensino, pesquisa e extensão; e interações entre instituição e comunidade (projetos, campanhas, ações). Refletir sobre essas realidades e cenários em conjunto com a equipe acadêmica deve objetivar a criação de uma visão compartilhada das responsabilidades e funções inerentes às ações institucionais intencionalmente planejadas. Espera-se, ainda a partir dessas ações coletivas, impactar especialmente o professor para que seu fazer cotidiano seja fundamentado por mediações de aprendizagem e desenvolvimento sustentadas por um planejamento intencional, consciente, competente e reflexivo do ensino. As atividades podem ser diversas: entrevistas individuais ou coletivas; conversas informais com profissionais, estudantes e familiares; trabalhos e projetos com equipes multiprofissonais; elaboração de assessorias e formação continuada aos diversos profissionais no âmbito do conhecimento psicológico; parceria com programas ou instituições para atendimento psicológico, jurídico, médico, assistencial e outros visando futuros encaminhamentos ou projetos; etc.

\section{Escuta psicológica}

Para realizar o mapeamento institucional é primordial o desenvolvimento de métodos de observação das situações e relações nos contextos específicos em que ocorrem. Articulado a esses métodos, porém, é necessário que o psicólogo desenvolva competências para criar estratégias de escuta psicológica das vozes institucionais e para compreender os aspectos intersubjetivos presentes nos processos relacionais do contexto escolar.

Acredita-se que, a partir de uma análise institucional crítica e reflexiva sobre as inúmeras vozes 
da escola presentes nas concepções e nas formas de organização, novas ações serão configuradas para a atuação psicológica na educação superior. Será possível o arejamento de discursos, significados e sentidos presentes nas falas e comunicações, oportunizando aos próprios atores a percepção das possíveis contradições e rupturas presentes no seu contexto, bem como a reflexão e a conscientização acerca de sua prática exitosa, do seu papel social e das competências que lhe são exigidas na formação profissional e pessoal.

A intervenção institucional da Psicologia Escolar não pode prescindir, portanto, de uma escuta psicológica específica, com o objetivo de fomentar processos de implicação dos profissionais quanto à mediação do desenvolvimento pessoal dos estudantes visando o sucesso acadêmico. Essa escuta não se caracteriza por um modelo "clínico-médico", orientado pelo paradigma dicotômico "saúde $x$ doença", já bastante criticado na literatura sobre Psicologia Escolar e também completamente descartado neste trabalho. Trabalhar com uma escuta psicológica coloca o psicólogo em situação de ouvir e compreender a singularidade das demandas, mas também de investigá-las e questioná-las, buscando, com lucidez, gerir a intersubjetividade presente nas relações.

Para desenvolver essa escuta, o psicólogo escolar deverá, de forma sensível, ética e cuidadosa, procurar estar com o outro e com o coletivo, perscrutar os fenômenos psicológicos e interpsicológicos, encontrar o sujeito, o grupo e a instituição na interdependência expressa em suas ações, histórias, significados e afetos. É necessário disponibilizar-se a ouvir, ver, sentir e viver indicadores objetivos, subjetivos e simbólicos do amálgama dialético entre o psíquico e o social; reconhecer os próprios envolvimentos pessoais, suas escolhas e sentimentos, mobilizados no espaço intersubjetivo.

Para que essas complexas vozes sejam compreendidas, o psicólogo não poderá prescindir de um arcabouço teórico advindo dos conhecimentos científicos de sua área. Mas, também deve aliar à fundamentação teórica uma sensibilidade para perceber e perscrutar processos intersubjetivos provenientes de um envolvimento ético com sujeitos que se encontram, muitas vezes, em posições diferentes, mas que atuam ressignificando os sentidos da singularidade e da complexidade do fenômeno compartilhado. A escuta psicológica recupera e compreende ativamente o sujeito no interior dos sistemas simbólicos relacionais, apontando caminhos para a mediação intencional de desenvolvimentos pelas ferramentas teóricas que a ciência psicológica disponibiliza.

Esse espaço de escuta na atuação dos psicólogos escolares deve desencadear ações originadas tanto da urgência do cotidiano escolar quanto nas atividades planejadas intencionalmente, desenvolvendo a competência para torna-se ouvinte de um cenário multifônico. Cenário que, geralmente, grita verdades isoladas, preconceitos consolidados, dificuldades intransponíveis; mas, que também sussurra pequenas conquistas, barreiras superadas, sucessos inesperados. O grande desafio é transitar por esse complexo contexto aprendendo a não isolar os significados e sentidos do coro de vozes; a não amenizar conflitos ou camuflar contradições, mas recolocar em circulação falas e discursos produzidos na ambiguidade e na diversidade; a escutar, de forma global e institucional, os pedidos de ajuda disfarçados nas queixas; a provocar a ressignificação das demandas, contraditórias ou imaginárias, introduzindo-as em uma ordem simbólica; a reverberar as vozes tensionadas de volta aos seus autores, mediando conscientização pessoal e coletiva a partir de outras escutas, individuais e institucionais.

A circulação de sentidos, afetos, dores, esperanças, frustações, conquistas, abandonos, sucessos e tantos outros fenômenos subjetivos e intersubjetivos que comparecem no contexto acadêmico, clamam por uma escuta qualificada cientificamente e comprometida eticamente. Esta deverá auxiliar uma intervenção competente que não adapte, adeque, normatize e naturalize esses fenômenos, mas que os recoloque enquanto manifestações legítimas de sujeitos que criam e recriam, vivem e revivem, dinamicamente, seus próprios processos de desenvolvimento enquanto trabalham o ensino e a aprendizagem. 


\section{Gestão de políticas, programas e processos educacionais nas IES}

Acredita-se que neste eixo de atuação o psicólogo escolar assessoraria diversificadas ações ligadas à gestão institucional. Essas ações poderiam ir desde a elaboração do Projeto de Desenvolvimento Institucional e do Projeto Pedagógico Institucional até o acompanhamento dos procedimentos avaliativos, fazendo parte da Comissão Própria de Avaliação prevista no Sistema Nacional de Avaliação da Educação Superior (SINAES) (Brasil, 2004), colaborando no planejamento e execução da autoavaliação institucional. Dependendo da natureza administrativa da IES, sua localização, características e demandas, a Psicologia Escolar poderá acompanhar os variados programas e projetos educacionais que, ao serem implementados, podem gerar alterações às dinâmicas instaladas.

Além destas, o psicólogo escolar poderá participar, acompanhar ou coordenar algumas outras ações como: processo de gestão institucional e indicadores de compromisso social presentes nas relações entre instituição e sociedade (projetos, campanhas, ações); projetos de acolhimento e informações aos calouros; programas de ambientação a novos docentes e funcionários; assessoria à definição e reformulação dos perfis docentes, discentes e técnicos; programas de formação continuada para docentes, coordenadores de cursos e funcionários técnico-administrativos; e políticas internas de apoio ao desenvolvimento individual ou institucional.

Como estratégias metodológicas para a ação institucional da Psicologia Escolar nas IES, defende-se a utilização de instrumentos de observação e análise dos contextos e dos processos intersubjetivos, como os apresentados no mapeamento institucional e na escuta psicológica. A organização institucional se estrutura em ações, produções, discursos, falas e comunicações cujos significados e sentidos fazem eco aos papéis sociais e competências que são exigidas para esse contexto; escutá-los pelas vias da Psicologia Escolar pode oportunizar transformações em coautoria e com responsabilidades partilhadas.

\section{Propostas pedagógicas e funcionamento de cursos}

Com relação à esse eixo de atuação, o psicólogo escolar poderia colaborar na análise das diretrizes e parâmetros curriculares que norteiam o trabalho pedagógico em cada curso, juntamente aos coordenadores pedagógicos e professores, acompanhando o processo de ensino e aprendizagem na vinculação às Diretrizes Curriculares Nacionais (DCN) (Brasil, 2003). Esse profissional poderia atuar, especialmente, no que diz respeito às concepções de aprender e ensinar; e à definição e aos indicadores de objetivos, conteúdos e orientações didáticas para as diferentes áreas de conhecimento. Poderia, ainda, sob outra ótica e também em parceria com coordenadores, analisar os Projetos Pedagógicos dos Cursos, visando a assessoria à processos de desenvolvimento de competências para o corpo docente e discente e à organização do currículo de forma ampliada (fundamentos e pressupostos, atividades pedagógicas, matriz curricular, seleção e integração de conhecimentos e competências). Essas análises ajudariam a evidenciar as concepções subjacentes e orientadoras de educação, ensino, desenvolvimento, aprendizagem e processos de avaliação que os profissionais possuem, favorecendo a conscientização e intencionalidade nas práticas educativas.

Em algumas Instituições de Ensino Superior, motivadas pelas diretrizes para a avaliação institucional prevista no SINAES (Brasil, 2004), foram implantados os Núcleos Docentes Estruturantes. Esse seria um locus favorável à ação do psicólogo escolar, especialmente quanto a operacionalizar e valorizar a política de formação de professores, coordenadores e gestores; incentivar modalidades diversificadas de ensino e desenhos curriculares diferenciados para atender às DCN; assessorar coordenadores de cursos (de forma presencial e à distância) e equipes do próprio núcleo docente quanto ao planejamento de pesquisas sobre o percurso acadêmico dos estudantes, indicadores de evasão ou de sucesso acadêmico, expectativas discente, acompanhamento de egressos e outros temas e políticas institucionais. 


\section{Perfil do estudante}

Especialmente quanto ao perfil do estudante, um acompanhamento e assessoramento no que se refere ao seu desenvolvimento poderia se caracterizar como mais uma das dimensões da atuação do psicólogo escolar nesse seguimento. Essa ação não se coaduna a um acompanhamento psicoterápico voltado, prioritariamente, à resolução de problemas acadêmicos ou socioafetivos dos estudantes. A compreensão do perfil deve favorecer a ampliação das análises para subsidiar uma ação institucional e coletiva e não reduzi-la a um "tratamento individual" de "alunos-problema". Ainda que o psicólogo escolar possa desenvolver espaços para escuta dessas e de outras demandas estudantis, elas devem ser analisadas e discutidas com o discente de forma contextualizada, levando em consideração as dinâmicas institucionais, as caraterísticas do ensino superior, as especificidades de cada curso, a história de vida do estudante e as relações intersubjetivas entre pares e docentes, visando um processo de conscietização do estudante acerca de suas potencialidades, autonomia, recursos e competências.

Institucionalizadas nos projetos pedagógicos de cada curso, as DCN orientam que perfis profissionais estruturem-se com base no desenvolvimento de competências e não mais a partir de uma sobrecarga conteudista de informações. Para isso, a ação da Psicologia Escolar torna-se bastante útil no sentido de oportunizar discussões acerca do desenvolvimento adulto e, para além do treino de habilidades ou capacidades específicas, de uma construção relacional de competências intencionalmente ampliadas no percurso da formação profissional.

Assim, o psicólogo escolar poderia desenvolver pesquisas que possibilitassem o conhecimento do perfil dos estudantes, ingressantes e concluintes, em especial suas expectativas, aspectos sociodemográficos, econômicos e familiares, bem como suas relações com o processo de formação, de escolha profissional e de construção da cidadania. Também poderia elaborar, junto aos coordenadores de curso e corpo docente, estratégias para verificar se e como os estudantes desenvolvem, em sua trajetória de formação, competências etico-políticas, socioeducativas, pessoais e interpessoais, além das tecnicocientíficas esperadas (Marinho-Araujo, 2009, 2014a).

$\mathrm{Na}$ perspectiva da relação instituição-estudante, o psicólogo escolar poderia assessorar processos de coordenação e gestão pedagógica quanto ao acompanhamento dos desenhos curriculares e metodológicos, a partir de análises acerca do impacto da educação superior no perfil esperado e nas competências desenvolvidas. Assim, os percursos acadêmicos dos estudantes, suas escolhas, avanços e dificuldades poderiam ser analisados à luz do empenho e compromisso da instituição com uma formação de qualidade, da permanência de todos os estudantes com dignidade e da busca constante pelo sucesso acadêmico.

As possibilidades de atuação do psicólogo na educação superior não se esgotam nas dimensões aqui trabalhadas, que constituíram-se em breves exercícios para ilustrar o amplo espaço de ações que poderiam estar a cargo da Psicologia Escolar na educação superior. Essas ações, em síntese, teriam como meta expandir os indicadores de melhoria da qualidade dos cursos oferecidos nas IES e sinalizar o quanto essa qualidade impacta e agrega no desenvolvimento pessoal e profissional, individual e coletivo de estudantes, docentes, gestores, especialistas e demais atores institucionais nesse fértil e complexo contexto de formação profissional.

\section{Considerações Finais}

Segundo Vygotsky (1926/1999, 1926/2003, 1931/2000) e Luria (1990), a estrutura da atividade cognitiva não permanece estática ao longo das diversas etapas do desenvolvimento histórico humano, pois as formas mais complexas dos processos psicológicos variam quando condições e materialidades da vida sociocultural mudam e quando o conhecimento se transforma. A educação superior, como fértil contexto para o desenvolvimento adulto e para a produção de conhecimento, pode ser ricamente explorada como fonte de saltos qualitativos e alterações fundamentais na atividade psicológica humana. 
Nessa direção, a intervenção do psicólogo escolar deve estar voltada, nesse tempo e espaço de formação pessoal e profissional, para a construção e consolidação de princípios, compromissos e responsabilidades transformados coletivamente a partir das vivências e aprendizagens de todos os atores na educação superior (estudantes, docentes, coordenadores, gestores). Para exercer a promoção de avanços ao desenvolvimento de competências desses participantes, o psicólogo escolar deverá considerar a forte interdependência entre a cultura institucional e a subjetividade dos envolvidos, expressa tanto nas relações de trabalho e escolhas profissionais quanto em expectativas, desejos, pensamentos e sentimentos pessoais. Assim, sustenta-se, como meta principal de sua intervenção, a mediação intencional da conscientização de sujeitos adultos, imprimindo proatividade, autonomia e independência aos rumos profissionais, bem como potencializando desejos e intenções ao desenvolvimento pessoal (Marinho-Araujo, 2009, 2010, 2014a).

Neste artigo, defendeu-se a educação superior como fértil campo para uma ação pautada na especificidade científica e profissional da Psicologia Escolar, ampliada para além das já existentes contribuições. A intervenção psicológica na educação superior deverá estar ancorada em uma perspectiva de atuação institucional, coletiva e relacional, exigindo práticas, saberes e conhecimentos coadunados à especificidade da ciência psicológica e à identidade profissional do psicólogo escolar. É necessária, nessa perspectiva, a mobilização de diversos recursos de ordem pessoal, técnica e ética para a construção de competências teórico-metodológicas, operacionais, gerenciais, socioafetivas, estética e interpessoais que balizem a intervenção profissional, dialeticamente concebida a partir dos processos de formação.

Essas competências deverão subsidiar análises e intervenções que potencializem o sucesso acadêmico, a permanência digna e cidadã do discente, o desenvolvimento competente do seu perfil de forma coadunada às dinâmicas institucionais, o comprometimento coletivo de todos os atores, os processos de subjetivação e conscientização das concepções de desenvolvimento e de aprendiza- gem, a mediação intencional e outras dimensões já sinalizadas anteriormente. Essas práticas profissionais deverão emergir da participação no cotidiano dos contextos institucionais e das realidades socioculturais.

Ressalta-se que as amplas prospecções de atuação institucional do psicólogo nas IES não se confundem com a formação que a Psicologia, enquanto saber científico, tradicionalmente oferece a diversos cursos de graduação no país. É reconhecido o espaço que a área ocupa em cursos de formação de professores (Licenciaturas, Pedagogia), por meio de diversas disciplinas (Psicologia da Educação, Psicologia da Aprendizagem, Psicologia do Desenvolvimento e outras).

É também recorrente a presença da Psicologia em cursos na área da saúde (Medicina, Enfermagem, Fonoaudiologia, Odontologia, Terapia Ocupacional e outros) ou nas áreas de Direito, Administração, entre outros. Entretanto, ainda que se reconheça a contribuição da Psicologia para outros perfis profissionais como de extrema relevância, alerta-se para que a atuação da Psicologia Escolar na educação superior não se reduza aos fundamentos ou à complementação da formação nos cursos de graduação de várias áreas. A função do psicólogo escolar nesse contexto, enquanto profissional fundamentado em teorias, conceitos, metodologias e instrumentos psicológicos, não pode ser confundida com a docência, seja na formação inicial ou continuada, em cursos de aperfeiçoamento ou de pós-graduação, ainda que uma de suas funções seja o trabalho junto aos professores.

Defende-se que a atuação da Psicologia deva ter, na educação superior, a função de orientar e alavancar formas coletivas igualmente comprometidas com a qualidade dessa formação, visando o desenvolvimento da cidadania com responsabilidade, competências e consciência. Assim, as contribuições que a a área pode e deve oferecer à educação superior, considerando os múltiplos e diversificados campos de desenvolvimento psicológico presentes nesse contexto, devem ter vínculos estreitos com uma postura crítica exercida no interior das instituições educativas, para oportunizar transformações ideológicas e éticas que se fazem neces- 
sárias, sustentadas em intervenções coerentes com a dimensão historicacultural dos sujeitos.

Acredita-se que o psicólogo escolar, atuando cotidianamente no interior da educação superior, deve ter clareza de importantes dimensões para um fazer competente, como por exemplo, a fundamentação teórico-conceitual acerca do desenvolvimento psicológico humano, em especial do sujeito adulto, e o planejamento intencional de ações práticas coletivamente ampliadas nos âmbitos institucional e sociopolítico das IES. A conscientização que esse profissional poderá mediar, engajado no processo educativo cotidiano no interior das IES, pressupõem uma mudança no paradigma de intervenção e de pesquisa: do problema localizado no estudante para as possibilidades coletivas de desenvolvimento propiciadas pela instituição e seus processos, programas, sistemas, políticas de gestão, de avaliação e, principalmente, pelas potencialidades originárias nas relações inter-subjetivas dos sujeitos que ativamente ressignificam esse contexto e a si próprios (Marinho-Araujo, 2009, 2014a). Assim, deve ocupar-se da formação humana e da construção da cidadania, considerando, para isso, questões subjetivas e contextuais com desdobramentos coletivos e institucionais.

Espera-se, por fim, com as reflexões e modelo apresentados neste artigo, que a implementação das políticas públicas contemporâneas na educação superior brasileira anunciem um oportuno espaço profissional e de pesquisa para a Psicologia Escolar. Entre as práticas emergentes da área, esse é um importante contexto a ser agregado, visando o acompanhamento crítico, o estudo do impacto dessas conjunturas sociopolíticas e sua influência no perfil, na aprendizagem e no desenvolvimento dos estudantes e demais sujeitos presentes nessa modalidade de ensino.

\section{Referências}

Almeida, L., Marinho-Araujo, C. M., Amaral, A., \& Dias, D. (2012). Democratização do acesso e do sucesso no ensino superior: uma reflexão a partir das realidades
Bariani, I. C. D., Buin, E., Barros, R. C., \& Escher, C. A. (2004). Psicologia Escolar e Educacional no ensino superior: análise da produção científica. Psicologia Escolar e Educacional, 8(1), 17-27.

Bisinoto, C., \& Marinho-Araujo, C. M. (2011a). Psicologia Escolar na educação superior: atuação no Distrito Federal. Psicologia em Estudo, 16(1), 111-122.

Bisinoto, C., \& Marinho-Araujo, C. M. (2011b). Psicologia Escolar na educação superior: construindo possibilidades diferenciadas de atuação. In R. S. L. Guzzo e C. M. Marinho-Araujo (Orgs.), Psicologia Escolar: identificando e superando barreiras (pp.193-214). Campinas: Alínea.

Bisinoto, C., \& Marinho-Araujo, C. M. (2014). Serviços de Psicologia Escolar na educação superior: uma proposta de atuação. In R. S. L. Guzzo (Org.), Bastidores da escola e desafios da educação pública: a pesquisa e a prática em Psicologia Escolar (pp.277-296). Campinas: Átomo \& Alínea.

Bisinoto, C., Marinho-Araujo, C. M., \& Almeida, L. S. (2011). A atuação da Psicologia Escolar na educação superior: algumas reflexões. Revista Portuguesa de Pedagogia, 45, 39-55.

Brasil. Ministério da Educação. (2003). Parecer n 67, de 11 de março de 2003. Referencial para as Diretrizes Curriculares Nacionais - DCN dos Cursos de Graduação. Brasília: Autor.

Brasil. Presidência da República. (2004). Lei nº 10.861, de 14 de abril de 2004. Institui o Sistema Nacional de Avaliação da Educação Superior - SINAES e dá outras providências. Brasília: Autor.

Brasil. Presidência da República. (2005). Lei nº 11.096, de 13 de janeiro de 2005. Institui o ProUni - Programa Universidade para Todos. Brasília: Ministério da Educação.

Brasil. Presidência da República. (2007). Decreto n 6.096, de 24 de abril de 2007. Institui o Programa de Apoio a Planos de Reestruturação e Expansão das Universidades Federais - REUNI. Brasília: Ministério da Educação.

Brasil. Presidência da República. (2012). Decreto n 7.824, de 11 de outubro 2012. Regulamenta a Lei no 12.711, de 29 de agosto de 2012, que dispõe sobre o ingresso nas universidades federais e nas instituições federais de ensino técnico de nivel médio. Brasília: Ministério da Educação.

Caixeta, J. E., \& Sousa, M. A. (2013). Responsabilidade social na educação superior: contribuições da Psicologia Escolar. Revista Semestral da Associação Brasileira da Psicologia Escolar e Educacional, 17(1), 133-140.

Dole, A. A. (1981). College psychology as a subspecialization. Professional Psychology: Research \& Practice, 12(3), 294-301. 
Farrell, P., Jimerson, S. R., Kalambouka, A., \& Benoit, J. (2005). Teachers' perceptions of school psychologists in different countries. School Psychology International, 26(5), 525-544.

Ferrer-Sama, P. (2008). Analysis of the data and discussion. In M. Katzensteiner, P. Ferrer-Sama, \& G. Rott (Orgs.), Guidance and counselling in higher education in European Union Member States (pp.325-335). Danmark: Narayana Press.

Guzzo, R. S. L., \& Mezzalira, A. S. C. (2011). 2008 - ano da educação para os psicólogos: encaminhamentos e próximos passos. In C. M. Marinho-Araujo \& R. S. L. Guzzo (Eds.), Psicologia Escolar: identificando e superando barreiras (pp.11-31). Campinas: Alínea.

Instituto Nacional de Estudos e Pesquisas Educacionais Anísio Teixeira. (2014). Censo da educação superior 2012: resumo técnico. Recuperado em outubro 10, 2015, de http://portal.inep.gov.br/web/censo-daeducacao-superior/censo-da-educacao-superior

Leontiev, A. (2004). O desenvolvimento do psiquismo. São Paulo: Centauro.

Luria, A. R. (1990). Desenvolvimento cognitivo. São Paulo: ĺcone.

Marinho-Araujo, C. M. (2009). Psicologia Escolar na educação superior: novos cenários de intervenção e pesquisa. In C. M. Marinho-Araujo (Org.), Psicologia Escolar: novos cenários e contextos de pesquisa, formação e prática (pp.155-202). Campinas: Alínea.

Marinho-Araujo, C. M. (2010). Psicologia Escolar: pesquisa e intervenção. Em Aberto, 83(23), 15-35.

Marinho-Araujo, C. M. (2014a). Psicologia Escolar na educação superior: desafios e potencialidades. In R. S. L. Guzzo (Org.), Psicologia Escolar: desafios e bastidores na educação pública (pp.219-239). Campinas: Alínea.

Marinho-Araujo, C. M. (2014b). Intervenção institucional: ampliação crítica e política da atuação em Psicologia Escolar. In R. S. L. Guzzo (Org.), Psicologia Escolar: desafios e bastidores na educação pública (pp.153 -175). Campinas: Alínea.

Marinho-Araujo, C. M., \& Almeida, S. F. C. (2005). Psicologia Escolar: construção e consolidação da identidade profissional. Campinas: Alínea.

Maroldi, A. M. (2012). Psicologia Escolar: um estudo bibliométrico da literatura nacional (1962-2011) (Dissertação de mestrado não-publicada). Universidade Federal de Rondônia, Porto Velho.

Martín-Baró, I. (1996). O papel do psicólogo. Estudos de Psicologia (Natal), 2(1), 7-27.

Nunes, L. L., Alves, S. S., Ramalho, J. V., \& Aquino, F. D. S. B. (2014). Contribuições da perspectiva crítica de base histórico-cultural para a produção científica em psicologia educacional. Educação e Pesquisa, 40(3), 667-682.

Parker, I. (2007). Critical psychology: What it is and what it is not. Social and Personality Compass, 1(1), 1-15.

Price, K. W., Floyd, R. G., Fagan, T. K., \& Smithson, K. (2011). Journal article citation classics in school psychology: Analysis of the most cited articles in five school psychology journals. Journal of School Psychology, 49(6), 649-667.

Rede de Serviços de Apoio Psicológico no Ensino Superior. (2002). A situação dos serviços de aconselhamento psicológico no ensino superior em Portugal. Portugal: Autor.

Rede de Serviços de Apoio Psicológico no Ensino Superior. (2006). Estatutos. Portugal: Autor.

Sampaio, S. M. R. (2009). Explorando possibilidades: o trabalho do psicólogo na educação superior. In C. M. Marinho-Araújo (Org.), Psicologia Escolar: novos cenários e contextos de pesquisa, formação e prática (pp.203-219). Campinas: Alínea.

Sampaio, S. M. R. (2010). A Psicologia na educação superior: ausências e percalços. Em Aberto, 23(83), 95-105.

Sandoval, J., \& Love, J. A. (1977). School Psychology in higher education: The college psychologist. Professional Psychology, 8(3), 328-339.

Serpa, M. N. F., \& Santos, A. A. A. (2001). Atuação no ensino superior: um novo campo para o psicólogo escolar. Psicologia Escolar e Educacional, 5(1), 27-35.

Vygotsky, L. S. (1999). Teoria e método em Psicologia. São Paulo: Martins Fontes. (Originalmente publicado em 1926).

Vygotsky, L. S. (2000). Historia del desarrollo de las funciones psíquicas superiores. Obras escogidas. Tomo III. Madrid: Visor. (Originalmente publicado en 1931).

Vygotsky, L. S. (2003). O esclarecimento psicológico da educação pelo trabalho. In L. S. Vygotsky. Psicologia pedagógica (pp.181-195). Porto Alegre: Artmed. (Originalmente publicado em 1926).

Witter, G. P. (1999). Psicólogo escolar no ensino superior e a Lei de Diretrizes e Bases. In R. S. L. Guzzo (Org.), Psicologia Escolar: LDB e educação hoje (pp.83-104). Campinas: Alínea.

Zavadski, K. C., \& Facci, M. G. D. (2012). A atuação do psicólogo escolar no ensino superior e a formação dos professores. Psicologia USP, 23(4), 638-705.

Recebido: novembro 30, 2015

Aprovado: dezembro 21, 2015 
